\title{
A Study of Early/Slow VLF Perturbations Observed at Agra, India
}

\author{
Uma PANDEY ${ }^{1,2,3}$, Ashutosh K. SINGH ${ }^{2,5}, \mathrm{Om} \mathrm{P}_{\text {. SINGH}}{ }^{2}$, Birbal SINGH ${ }^{1}$, \\ and Vibhav K. SARASWAT ${ }^{4}$ \\ ${ }^{1}$ Department of Electronics and Communication Engineering, \\ Raja Balwant Singh Engineering Technical Campus, Bichpuri, Agra, India; \\ e-mail: pandeyuma68@gmail.com \\ ${ }^{2}$ Department of Physics, Raja Balwant Singh Engineering Technical Campus, \\ Bichpuri, Agra, India \\ ${ }^{3}$ Department of Electronics, Banasthali University, Rajasthan, India \\ ${ }^{4}$ Department of Physics, Banasthali University, Rajasthan, India \\ ${ }^{5}$ Department of Physics, SRM University, Tindola, Barabanki, India
}

\begin{abstract}
We present here the results of sub-ionospheric VLF perturbations observed on NWC $(19.8 \mathrm{kHz})$ transmitter signal propagating in the Earth-ionosphere waveguide, monitored at our low latitude station Agra. During the period of observation (June-December 2011), we found 89 cases of VLF perturbation, while only 73 cases showing early character associated with strong lightning discharges. Out of 73 events, 64 ( $>4 \%)$ of the early VLF perturbations are found to be early/slow in nature; the remaining 9 events are early/fast. The onset duration of these early/slow VLF perturbations is up to $\sim 5 \mathrm{~s}$. A total of 54 observed early events show amplitude change lying between $\pm 3.0 \mathrm{~dB}$, and phase change \pm 12 degree, respectively, and found to occur mainly during nighttime. One of the interesting results we found is that the events with larger recovery time lie far away from the VLF propagation path, while events with smaller duration of recovery are within the $\pm 50-100 \mathrm{~km}$ of signal path. The World Wide Lightning Location Network (WWLLN) data is ana-
\end{abstract}

Ownership: Institute of Geophysics, Polish Academy of Sciences;

(C) 2016 Pandey et al. This is an open access article distributed under the Creative Commons Attribution-NonCommercial-NoDerivs license,

http://creativecommons.org/licenses/by-nc-nd/3.0/. 
lysed to find the location of causative lightning and temporal variation. The lightning discharge and associated processes that lead to early VLF events are discussed.

Key words: early VLF perturbations, Transient Luminous Events (TLEs), Earth-ionosphere waveguide, lightning.

\section{INTRODUCTION}

Variations in the ionospheric D region due to the different geophysical phenomena lead to changes in the propagation conditions of very low frequency (VLF) waves propagating sub-ionospherically, which appears as change in the observed amplitude and/or phase of VLF transmissions (Thomson 2010). These changes in amplitude and/or phase of the VLF signal can be used as a diagnostic tool for the lower ionospheric disturbances related to the solar flares (Mitra 1974), auroral enhancement (Cummer et al. 1997), terrestrial gamma ray bursts (Inan et al. 1999), and ionospheric perturbations associated with seismic activity (Hayakawa et al. 1996).

Sub-ionospheric VLF transmission can also be used to probe the upper atmosphere and specifically the lower ionospheric processes associated with lightning discharge. Lightning causes lower ionospheric changes (i.e., D-region modification) first through the wave energy $(3-30 \mathrm{kHz})$ launched into the magnetosphere as "whistler" waves which can interact with radiation belt electrons and cause them to precipitate into the ionosphere. These disturbances are known as Lightning-induced Electron Precipitation (LEP) events (Rodger 2003) which perturb VLF transmitter signal (known as Trimpi). The intense electromagnetic pulse (EMP) radiated during powerful cloud to ground (CG) lightning discharges can also couple directly into the lower ionosphere producing transient localised D-region conductivity changes which is often manifested as sudden change in amplitude and/or phase of VLF signal (called early VLF event) propagating on a nearby path followed by a slower recovery to ambient level within 10-100 s.

The first observation of amplitude and phase perturbation on short time scale $(\sim 100 \mathrm{~s})$ was reported by M.L. Trimpi (Helliwell et al. 1973) during his time as field scientist from the VLF data recorded in Antarctica. Such perturbations in amplitude and/or phase of VLF transmission start with fast $(\sim 1 \mathrm{~s})$ onset followed by slower recovery $(\sim 100 \mathrm{~s})$, which, because of whistler induced electron precipitation, are now termed as "classic Trimpi". Armstrong (1983) discovered a new type of VLF perturbations whose onset was too soon (early) after the causative lightning in comparison to classic Trimpi and have comparatively faster decay time. This class of VLF perturbation is now referred to as "early" Trimpi (Inan et al. 1988) or early VLF perturbations (Haldoupis et al. 2004). The term early refers to the fact that the perturbations occur nearly in coincidence (within $20 \mathrm{~ms}$ ) with the lightning 
stroke (Inan et al. 1988, 1993), which distinguishes them from LEPs. Within early VLF events, early/fast events refer to those which are triggered within $<20 \mathrm{~ms}$ after the causative lightning and have rapid onset duration $<20 \mathrm{~ms}$ (fast), whereas early/slow events are characterised with comparatively larger onset duration of 0.5-2 s (slow) with a similar recovery signature. Early VLF events are characterised by slower recovery to ambient level in 10 to $180 \mathrm{~s}$ or more (Inan et al. 1996a, b). The studies of early VLF events have been carried out in last two decades, mostly at Stanford University (Inan et al. 1995, Moore et al. 2003), at University of Crete (Haldoupis et al. 2004, Mika et al. 2005), and University of Otago (Rodger 2003, Dowden et al. 1996). Haldoupis et al. (2006) reported a new category of early VLF, namely "early/slow" events having the longer onset duration, of $<100 \mathrm{~ms}$ to couples of seconds, with similar signatures of recovery. Mika (2007) have done the detailed work on these events. Mika and Haldoupis (2008) from EuroSprite2003 campaign data show that there is one-to-one correlation between sprite and early/fast events. Singh and Singh (2010) reported early VLF events for the first time from Indian sub-continent station at Agra. The reported events show early/slow character and were much fewer in number. Results from EuroSprite-2007 data (NaitAmor et al. 2010) further support that there occurs one-to-one correlation between sprite and early/VLF events. Recently, Inan et al. (2007) made observations of LEP on the DEMETER satellite, constraining the electron energies to $100-300 \mathrm{keV}$, and directly correlated the events with lightning data from a ground-based network. Nemec et al. (2010) discussed the influence of power line harmonic radiation on the VLF wave activity in the upper ionosphere with space borne study. Recent observation of EM emissions related to thunderstorms recorded on DEMETER are reported by many observers (Parrot et al. 2008, 2013; Błęcki et al. 2009, Pandey et al. 2013). Błęcki et al. (2009) reported first space registration of ELF/VLF signature of sprites recorded on DEMETER satellite during thunderstorm activity. More detailed discussion is given in Parrot et al. (2013) and references therein. Despite the 20 years of research since their discovery, the mechanism of "early" event production remains uncertain and a topic of current research. In this paper we will discuss the early VLF perturbations specifically early/slow events and their relation with lightning and to Transient Luminous Events (TLEs) occurring above it.

TLEs are short lived flashes of light (sprites, elves, etc.) occurring above large thunderstorms in the stratosphere and mesosphere. On the basis of their characteristics shapes, lifetimes and altitudes, these optical emissions were divided in three categories as sprite, elves, and jets. Sprites are luminous discharges occurring above active thunderstorm centres and below the $\mathrm{E}$ region (i.e., altitudes between 40 and $85 \mathrm{~km}$ ) in association with cloud-to-ground $(+\mathrm{CG})$ or intra-cloud lightning strokes (Mika 2007). They have lifetime of 
tens of milliseconds. On the other hand, the elves are emissions of light due to electromagnetic pulse from the intense $(>60 \mathrm{kA}) \mathrm{CG}$ discharges (NaitAmor et al. 2010). They occur at $75-105 \mathrm{~km}$ altitudes with the lifetime of $\sim 1 \mathrm{~ms}$. They consists of a horizontally expanding ring of luminosity from 100 to $300 \mathrm{~km}$ and can attain up to $500 \mathrm{~km}$.

In this paper, we present the results of early VLF events to examine the characteristics at low latitude. For this purpose, a statistical study of the VLF signature of ionospheric perturbations associated with strong lightning during a relatively long term (6 months) period is done. The corresponding World Wide Lightening Location Network (WWLLN) data are analyzed to confirm their origin. In total we found 89 cases of VLF perturbation (not early VLF perturbation); out of these 89 , only 73 cases were associated with strong causative lightning occurring within the millisecond of onset of perturbation and fulfilling the characteristic definition of early VLF perturbation considered in this analysis. A total of 64 early VLF perturbations recorded at our station show early/slow character. Characteristic and temporal variation of theses early VLF events with possible cause are discussed.

\section{EXPERIMENTAL SET UP}

Monitoring of phase and amplitude of VLF transmitter signals is in progress at our low latitude station Agra (geomag. latitude $27^{\circ} \mathrm{E}$, longitude $78^{\circ} \mathrm{N}$ ) since 1 August 2002. Bichpuri is located in rural area about $12 \mathrm{~km}$ west of Agra city where local electric and electromagnetic disturbances are low. Initially, we employed AbsPAL (Absolute Phase and Amplitude Logger) system (Dowden et al. 1994) and studied the effect of lightening on VLF propagation path (Singh and Singh 2010), but later it has been replaced by modified software based receiving system, i.e., Software based Phase and Amplitude Logger (SoftPAL) on 1 April 2010. Since then we are monitoring the phase and amplitude of three different signals having frequencies of $19.8 \mathrm{kHz}$ (NWC, Australia), $21.4 \mathrm{kHz}$ (NPM, Hawaii), and $24 \mathrm{kHz}$ (NAA, Cutler, Maine). In the present study, we have used the NWC $(19.8 \mathrm{kHz})$ transmitter signal to probe the transient D-region ionospheric perturbations.

\section{OBSERVATIONAL RESULTS}

VLF transmitter signal recording is done to study the lower ionospheric perturbations associated with different geophysical phenomena. We have analysed the six month VLF data recorded during 1 June to 31 December 2011 for the purpose of examining the possibility of early VLF events and the characteristics associated with them at our low latitude station. We have analysed the phase and amplitude of VLF signal data and found seventy four cases which appear to be matching with early events characteristics. VLF events showing early characteristics are found in both, the amplitude as well 


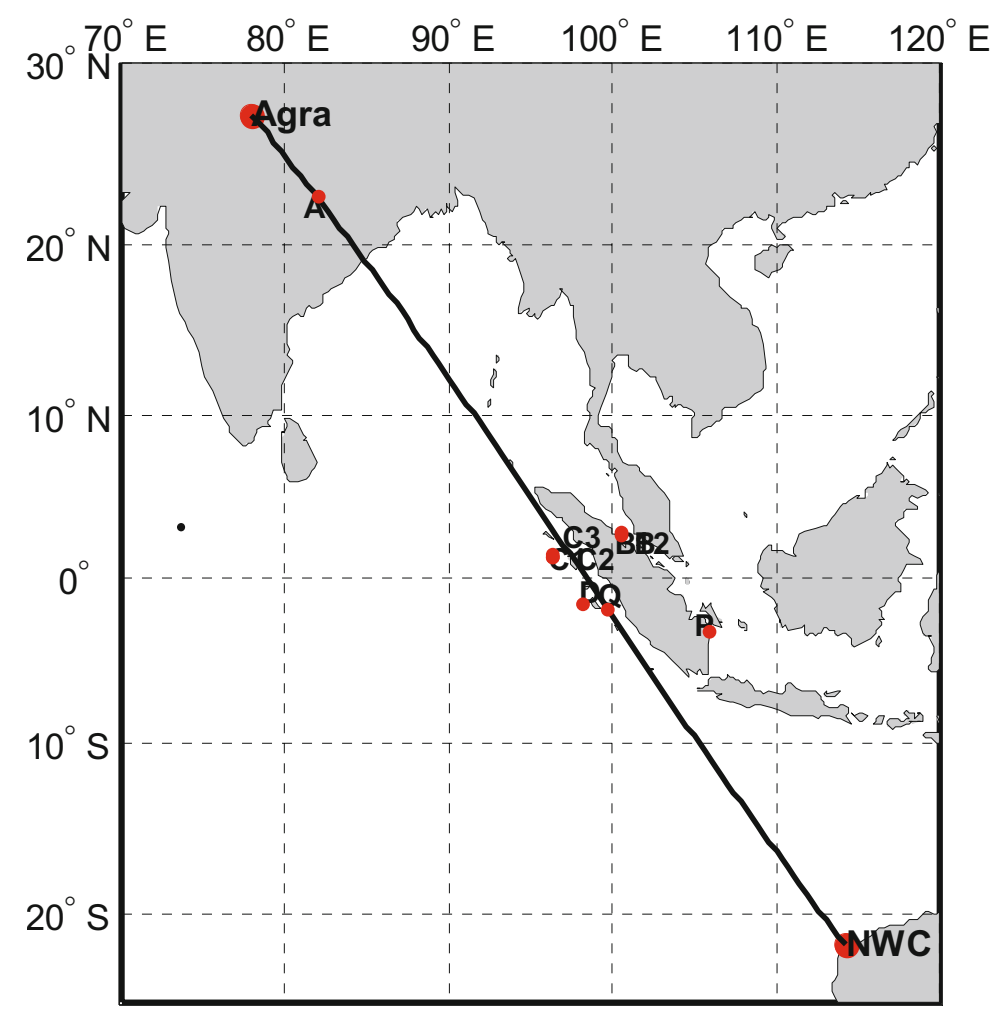

Fig. 1. The location of NWC-transmitter, receiver, and great circle path to Agra. WWLLN-determined locations of the lightning discharge associated with the early VLF events shown in Fig. 2a are marked as A; Fig. 2b as B1 and B2; Fig. 2c as C1, C2, and C3; Fig. 2d as D, Fig. 3a as P; and Fig. 3b as Q, respectively.

as phase of the signal. In total, out of 73 events, we observed 54 events occur in nighttime and only 3 cases are observed in during the day. The remaining 16 events were observed during partial sunlit condition. Figure 1 shows the NWC transmitter (located at North West Cape, Australia), our low latitude receiving station Bichpuri (located in Agra, India), and corresponding transmitter-receiver great circle path (TRGCP) plotted by using an azimuthally equidistant projection centered at Agra. Analyzing the bulk of data of amplitude and phase recorded at our low latitude station Agra, a very short time scale perturbation in the VLF transmitter signal was observed, which occurred $<20 \mathrm{~ms}$ after the associated lightning discharge known as "early" Trimpi (Inan et al. 1988). It is found that 64 observed events have an onset duration of 1-5 s which exhibits an early slow character of the events. Analysis shows that only $\sim 26 \%$ of events were observed during the full 
sunlit or partial sunlit condition and the remaining were observed during nighttime, when the entire TRGCP remains in dark. We observe changes in amplitude and/or phase of the NWC signal during the six months period of our analysis, most of the changes in amplitude lies between $\sim 1$ to $3 \mathrm{~dB}$ and in case of phase it is $\sim 01$ to 12 degrees, respectively. Onsets of perturbation start in $<20 \mathrm{~ms}$ in amplitude and/or in phase after the causative lightning are considered in the category of early VLF perturbations. In this paper, we present here only early VLF perturbations caused by the direct modification of the ionosphere which is associated with the strong lightning. The majority of early type VLF events occurred basically in nighttime because of the least ionization during the nighttime when the TRGCP or a part of it is in dark, resulting in decreased attenuation in amplitude and/or in phase of the VLF transmitter signal. Only few cases $(13.5 \%)$ have been observed in the daytime. This is because of the presence of Sun as an ionization source which results in higher ionization and hence the lower VLF reflection height during the daytime. During the whole period of our analysis, only early VLF perturbations have been focused by us. Figure 2 shows the four typical examples of the early VLF events observed on NWC transmitter signal during the nighttime period and time of the associated lightning detected by WWLLN is indicated by the vertical dashed lines with the arrows. Locations of lightning associated with these events are shown in Fig. 1. The date and time of occurrences of these events are as follows: Fig. 2a shows the early VLF event recorded on 5 September 2011 at 20:41:54.7 UT on NWC transmitter signal and the corresponding lightning at 20:41:54.64319 UT (geogr. lat. 22.8157, geogr. long. 81.9665) detected by WWLLN associated with this event is labelled " $A$ " in Fig. 1. Figure $2 b$ shows the event recorded on 10 October 2011 at 18:49:07.8 UT and corresponding to this WWLLN detected two lightning events, one at 18:49:07.2417 UT marked as "B1" (geogr. lat. 2.8201, geogr. long. 100.4692) and the other at 18:49:07.662819 UT marked as "B2" (geogr. lat. 2.8155, geogr. long. 100.445), as shown in Fig. 1. Another example of early/slow VLF perturbation is shown in Fig. 2c, recorded on 23 October 2011 at 19:14:17.8 UT. WWLLN detected three lightning events in the vicinity of TRGCP: at 19:14:17.79465 UT (geogr. lat. 1.4715, geogr. long. 96.321), at 19:14:17.71936 UT (geogr. lat. 1.4803, geogr. long. 96.2696), and at 19:14:17.71003 UT (geogr. lat. 1.4631, geogr. long. 96.3422), labelled "C1", "C2", and "C3", respectively, in Fig. 1. Figure 2d represents an example of early/fast event recorded on 23 October 2011 at 19:37:24.2 UT, and corresponding to this event WWLLN detect a lightning at 19:37:24.147 UT (geogr. lat. -1.4009 , geogr. long. 98.1933) whose location is shown in Fig. 1 as "D". Further on, in Figs. 2c and d, an expanded view of one minute is presented to show onset duration of early/slow and early/fast events more clearly. It is obvious from the enlarged view that the 

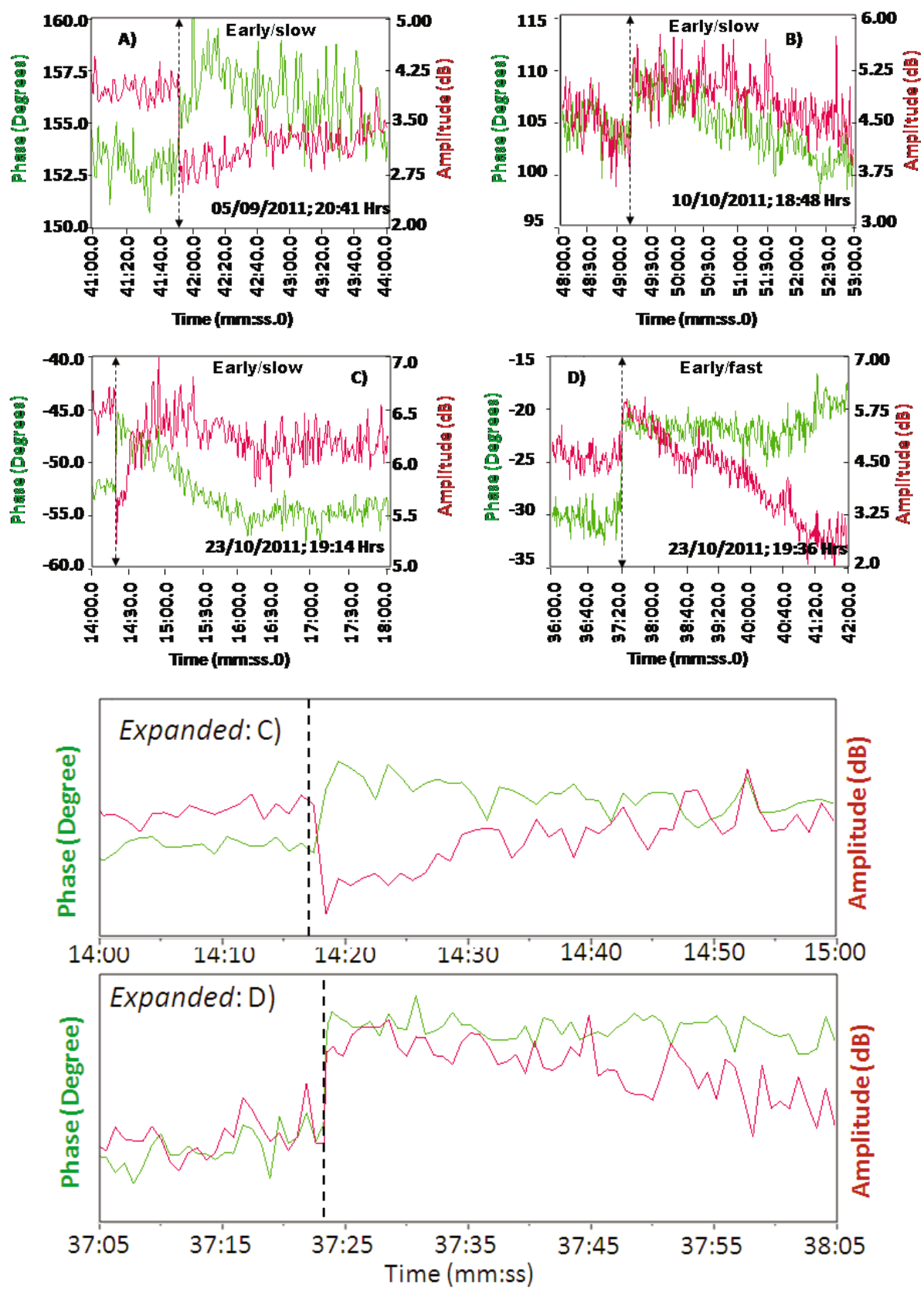

Fig. 2. Typical example of observed amplitude (solid-traces - red color) and phase (solid-traces - green color) perturbations on: (a) 5 September 2011 at 16:00:51.6 UT, (b) 10 October 2011 at 22:14:14.90 UT, (c) 23 October 2011 at 21:39:07.82 UT, and (d) 23 October 2011 at 21:59:59.80 UT. 

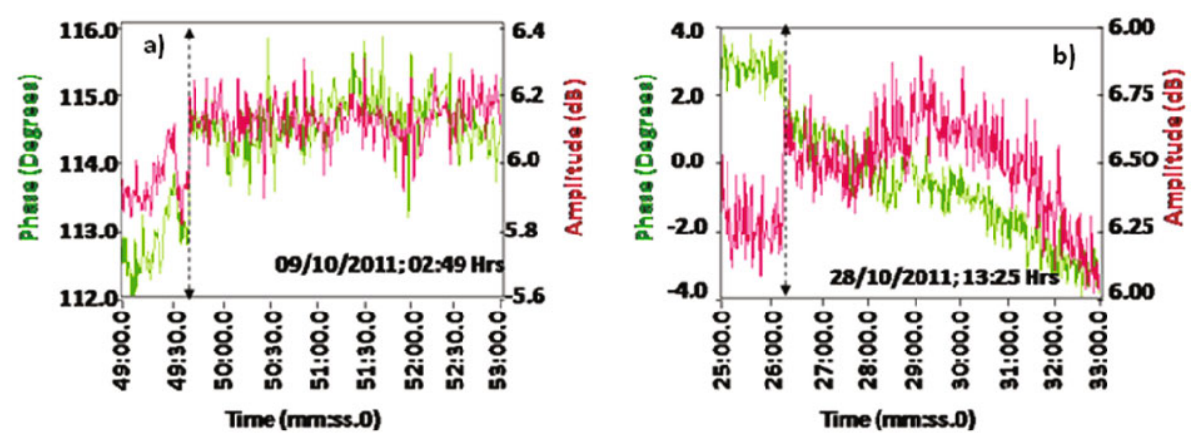

Fig. 3. Two typical examples of daytime early VLF event observed on: (a) 9 October 2011 at 02:49:37.7 UT and (b) 28 October 2011 at 13:26:11.0 UT.

event shown in Fig. 2c has onset duration of $1.6 \mathrm{~s}$ while Fig. $2 \mathrm{~d}$ has onset duration of $40 \mathrm{~ms}$.

Two examples of daytime early/slow VLF perturbation are shown in Fig. 3; Fig. 3a shows daytime early event occurred on 9 October 2011 at 02:49:37.5 UT on NWC transmitter signal. WWLLN detected strong lightning at 02:49:37.44458 UT (geogr. lat. -.1217, geogr. long. 105.9265) marked as "P" in Fig. 1 which is at a distance of $342 \mathrm{~km}$ from TRGCP, showing wide angle scattering. Another daytime event, recorded on 28 October 2011 at 13:26:10.8 UT is shown in Fig. 3b. Corresponding to this event, WWLLN detected lightning at 13:26:10.76931 UT (geogr. lat. -1.8829 , geogr. long. 99.5681) marked as $\mathrm{Q}$ in the vicinity of TRGCP (12 km from TRGCP).

\section{TEMPORAL VARIATION OF EARLY VLF PERTURBATIONS}

Statistical analysis is done to see temporal variation of early VLF events. For this we tried to plot the variation of early VLF events with respect to lightning activity. In Fig. 4, histograms show the change in amplitude and change in phase associated with early VLF perturbations on the NWC transmitter signal during the period of observation. We found that perturbations in phase are as high as 27 degrees and in case of amplitude it is as high as $\sim 3 \mathrm{~dB}$, respectively. A total of 64 events display amplitude changes between $-2.0 \mathrm{~dB}$ and $+2.0 \mathrm{~dB}$ and phase changes mainly between \pm 12 degrees. Only in 9 cases we found that the perturbations in amplitude are $\geq 2 \mathrm{~dB}$. We also measured the lateral distance (in $\mathrm{km}$ ) of the causative lightning to estimate the size of the region which is affected by lightning discharge and TLEs associated with it, as shown in Fig. 5.

The diurnal variation of occurrence of early VLF events on NWC during January to June 2010 is presented in Fig. 6a. We observe that most of the 

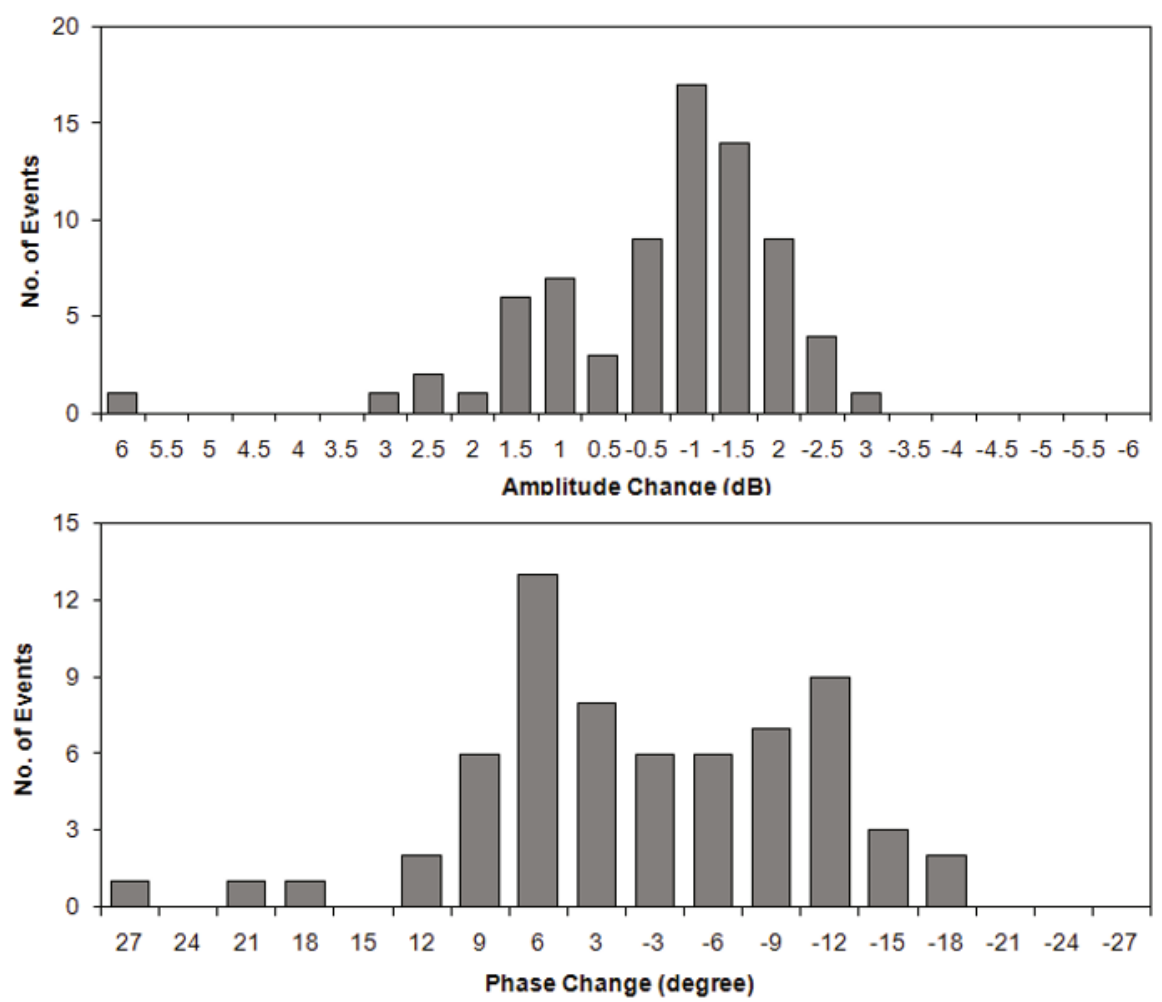

Fig. 4. Histograms of amplitude and phase perturbations associated with all early VLF events.

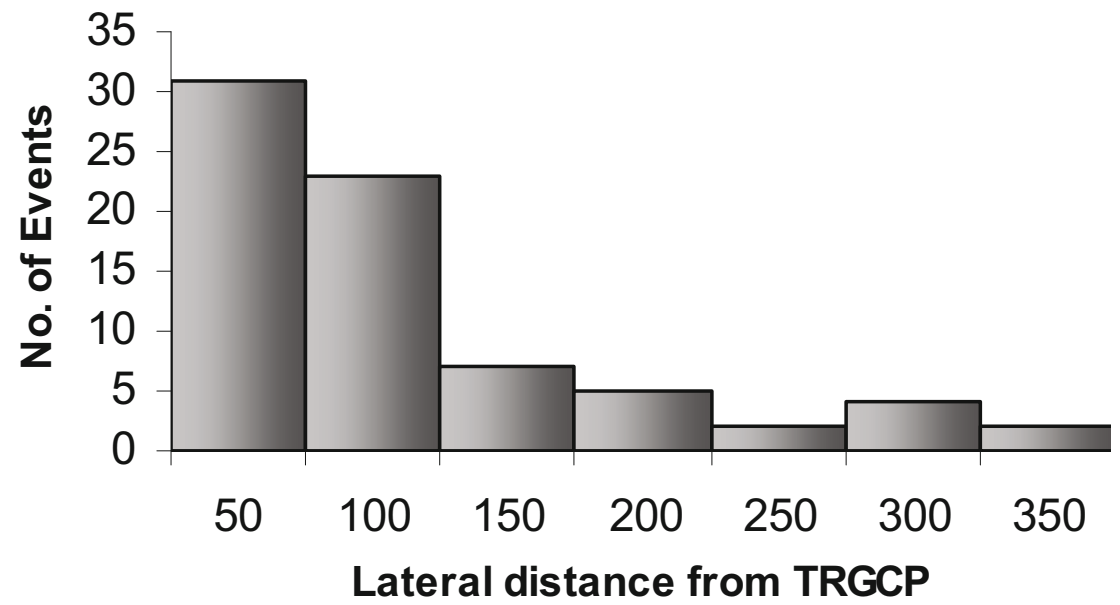

Fig. 5. Figure shows the lateral distance (in $\mathrm{km}$ ) of causative lightning discharges from TRGCP. 


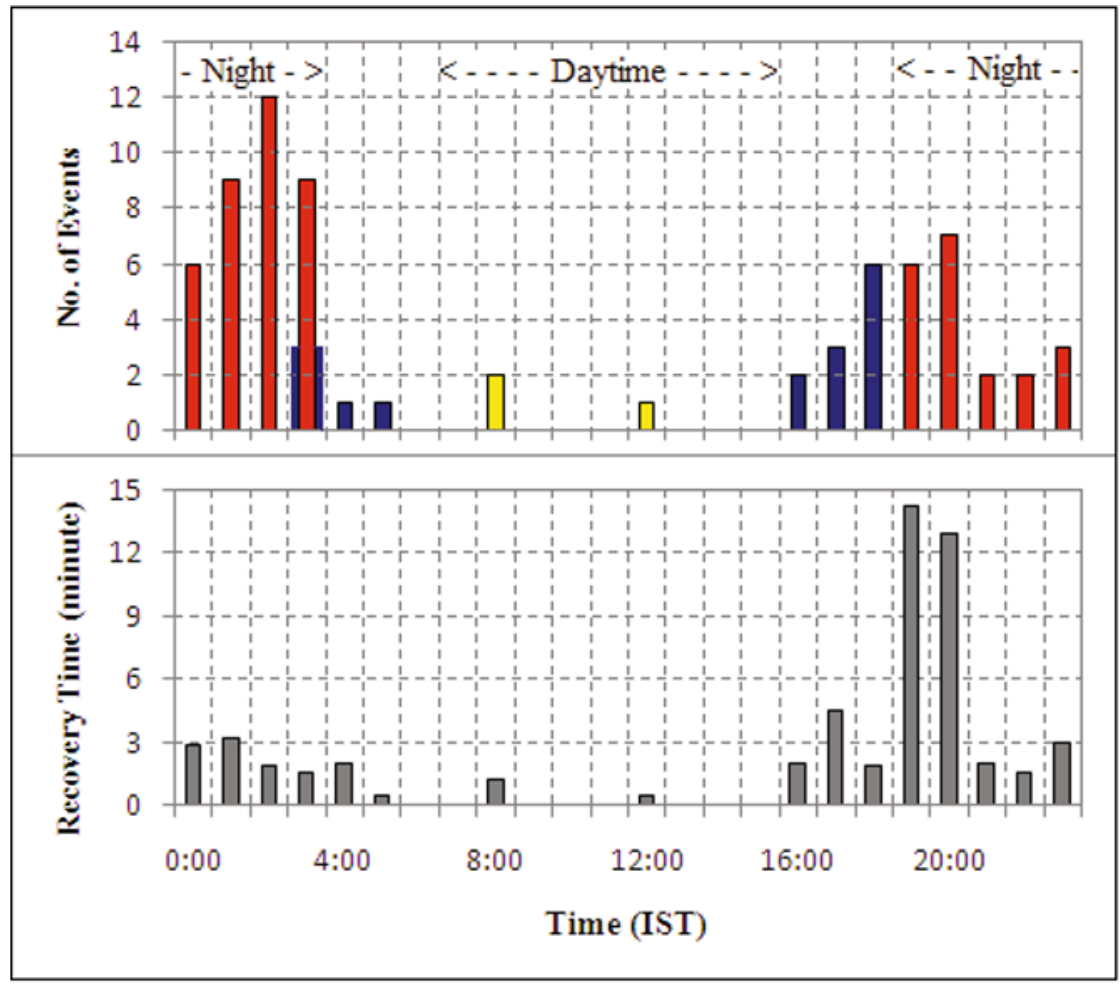

(a)

(b)

Fig. 6. Diurnal variation of early VLF events detected during January to December 2011 on NWC transmitter signal is shown in panel (a), while (b) shows the diurnal variation of recovery time during the period of observation. Red bar shows the events recorded when entire TRGCP is in dark, yellow bar - full sunlit condition, and blue bar - partial sunlit condition (IST - Indian Standard Time).

early VLF events occur during the nighttime, between 19:00 to 03:15 IST (Indian Standard Time), which is in accordance with the earlier reports from mid and high latitude. During the period of our study we found 54 events when entire TRGCP from NWC to Agra was in complete darkness (red bar) while only 3 events were found during full sunlit condition (yellow bar). The remaining 16 were found in partial sunlit condition (blue bar). Figure $6 \mathrm{~b}$ shows the variation of recovery time/relaxation time of different events observed during different parts of the day. For this we have grouped the events having recovery between $0.0-0.5 \mathrm{~min}$ as 0.5 , events with recovery between $0.5-1.0 \mathrm{~min}$ as 1.0 and so on. We grouped the events only if three or more events had recovery in that interval. We observe that daytime events have lesser recovery time compared to nighttime, but no correlation during night hours itself. In Fig. 7 we show the temporal variation of all early events dur- 


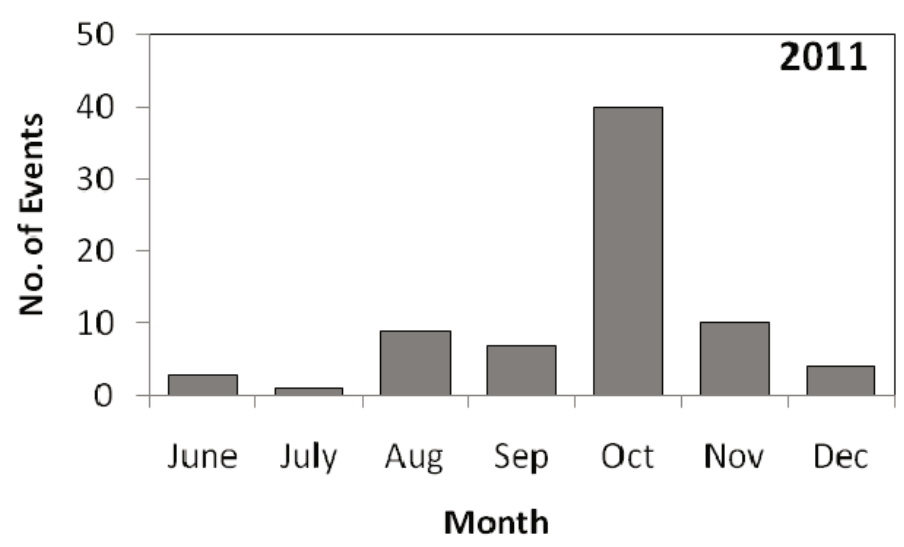

Fig. 7. Temporal variation of early VLF events detected during June to December 2011 on NWC transmitter signal.

ing the six month analysis period, and we found that the majority of the events are observed in the month of October; this is due to the high lightning activity in this month at low latitudes and also near the region of TRGCP of Agra to NWC.

\section{DISCUSSION}

During the period of our six month data monitoring, analysis of phase and amplitude of VLF signals are carried out at our low latitude station Agra. We observed different types of the early VLF events at our Agra station. All the 73 events reported here are associated with strong lightning discharges. Out of 73 events, $64(\sim 84 \%)$ of the early VLF perturbations are found to be early slow in nature, remaining 9 events are early/fast. A total of 54 events were recorded at nighttime when the entire TRGCP was in dark. First evidence of such observations was presented by Armstrong (1983) and then by Inan et al. (1988). After the discovery of early VLF events, many attempts were made to explain the mechanism of early VLF phenomena (Rodger 1999 and reference therein). Inan et al. (1995) presented the first convincing result showing a relation between the early VLF events and sprites occurring to the TRGCP but from the large distances from the receiver $(>2000 \mathrm{~km})$ and attributed these events to directional forward scattering from enhanced ionization associated with the lightning which is located to the TRGCP with the lateral extents of $\sim 100-500 \mathrm{~km}$. Dowden et al. (1996) presented the results of early VLF events in one-to-one correlation with sprites located around the TGRCP within $\sim 500 \mathrm{~km}$ and are attributed the wide-angle (omnidirectional) scattering from sprite generated columnar structures of ionization with shorter scale than the VLF wavelength. Strangeways (1996), 
Rodger (1999), Mika (2007) and references therein, presented the detail review of these events and made an attempt to explain the early VLF phenomena. The occurrence of the early VLF events can be explained by two different phenomena: first is the heating of lower ionosphere by strong quasi-electrostatic field generated by lightning discharges, resulting in conductivity changes of the lower ionosphere (Inan et al. 1991, 1996a, b), and the second is ionization which is produced by the transient luminous events (TLEs) like sprite halos or elves (Mika et al. 2005, 2006) which appears at the VLF reflection height to the lower altitudes (between 55 and $75 \mathrm{~km}$ ). Sustained heating could not be effective mechanism for the VLF perturbations, due to very short time of temperature relaxation. Location of the causative lightning associated with the events shown in Figs. 2a and 3c (A: $10 \mathrm{~km}$; C: 69,81 , and $82 \mathrm{~km}$, respectively) indicates that such perturbations were produced by the narrow angle forward scattering most likely by enhanced ionization from sprites, whereas the early VLF event shown in Fig. $2 \mathrm{~b}$ is associated with the lightning within 381 and $386 \mathrm{~km}$ of TRGCP employing a wide angle scattering of the VLF waves. Strong CG lightning as well as intra cloud (IC) lightning is the most probable cause for the early/ slow events presented in Fig. 2. Earlier observations show one-to-one association with sprite and early/slow events having onset duration 0.5-2 s (Inan et al. 1999, Haldoupis et al. 2006). Strong sprite activity is observed with the enhanced intra cloud lightning (Neubert et al. 2005). The gradual growth of amplitude and/or phase of early/slow event (i.e., longer onset duration of 0.5-2.0 s) are due to complex lightning consisting CG and IC lightning which produce primary and secondary ionization. This secondary ionization in the upper D region produced by EMP field of IC discharge is the likely cause for the longer onset duration of early/slow events.

On the other hand, in the daytime when optical measurements are not possible, the propagation condition of the $\mathrm{D}$ region is stable and the reflection height of VLF vary between the range of $70-75 \mathrm{~km}$, the VLF method can be used for the detection of sprites and elves (Dowden et al. 1996; Haldoupis et al. 2004, 2006). Farges et al. (2005) reported recently the characteristics of the red sprite during the daytime by using the infra-sound techniques. Kumar et al. (2008) showed that VLF waves can be used to detect a red sprite during the day. The evidences are shown in Glukhov et al. (1992) that sprite may be the reason of ionization to the lower ionosphere in the daytime at VLF reflection height of $70-75 \mathrm{~km}$ where the relaxation of electron density enhancement occurs in 10-100 s. VLF perturbations in the amplitude showing early character are detected in NWC transmitter signal during the daytime have longer recovery time and is most likely associated with sprites occurring in daytime near the receiver. The VLF perturbation shown in Fig. 3 exhibits similar onset after causative lightning as the events 
in Fig. 2, but have longer recovery. Event in Fig. 3a has a recovery time of 19 min, with causative lightning "P" at a distance of $436 \mathrm{~km}$, showing a wide angle and back scattering (Dowden et al. 1996), while the event shown in Fig. $3 \mathrm{~b}$ (recovery time $\sim 6 \mathrm{~min}$ ) is associated with the lightning at $9 \mathrm{~km}$ away from TRGCP marked as Q. This indicates a narrow angle scattering of the VLF signal. Gradual recoveries of long lasting VLF perturbations are likely due to long-lived ionospheric modifications generated in the uppermost D region, by EMPs emitted from powerful CG lightning discharges of either polarity (Haldoupis et al. 2013). These long enduring recoveries can also be attributed to the lengthy process of the mutual neutralization of negative and positive ions at altitudes below $50 \mathrm{~km}$ which persist up to $20 \mathrm{~min}$ (Kumar and Kumar 2013), consistent with theoretical prediction of Lehtinen and Inan (2007). These early/slow events are likely due to red sprites during the day or short lived plasma column near the VLF reflection height or a combination of both. Some of the recorded early VLF events exhibit long recovery associated with the causative lightning at larger distances from TRGCP relative to the distance of typical early/slow VLF events which can be attributed to larger scattering pattern and hence a different physical mechanism.

Figure 5 shows the lateral distance (in $\mathrm{km}$ ) of causative lightning discharges from TRGCP. Lightning discharges associated with 54 early VLF events observed during nighttime (out of 73 early VLF events) occurred within $100 \mathrm{~km}$ of TRGCP, exhibiting narrow angle scattering. Other 20 events show wide angle scattering having causative lightning within 100$450 \mathrm{~km}$ from TRGCP. Diurnal variation of early VLF events shown in Fig. 6 shows that $\sim 74 \%$ (54 events) of the early VLF events occur in nighttime during the period of observation. This preference may be due to either the red sprite occurring less often due to the fewer existence of short-lived plasma column near the VLF reflection height during daytime. Also the recovery time of daytime early/slow events is smaller compared to nighttime early/slow events, which indicates smaller relaxation time for electron density enhancement at VLF reflection heights during the day. Temporal variation during the period of observation (as shown in Fig. 7) exhibits enhanced lighting activity and hence TLEs in India-Oceania region in the months of October-November.

\section{CONCLUSION}

The recent results on early VLF perturbations are presented, which are observed on NWC transmitter signal during June to December 2011 at our low latitude station Agra. Analysis of VLF data made it possible to determine and study different types of VLF perturbations in the amplitude and/or phase of NWC signal received at our station. Some of the major findings are sum- 
marized as follows: most of the observed early events show amplitude change lying within $\pm 2.0 \mathrm{~dB}$, and phase change of \pm 12 degrees, respectively, and are found to occur mainly during nighttime. The onset duration of these early VLF perturbations is up to $\sim 5 \mathrm{~s}$, showing early/slow character. The occurrence rate of early VLF perturbation in the daytime is found to be less as compared to nighttime and has a faster recovery time, which may be due to faster electron relaxation time of ionization produced by daytime TLEs. Events with longer recovery are distributed at a longer distance from the TRGCP relative to typical early slow events, showing a different mechanism for events with long recovery. Daytime early VLF perturbations have received the less attention of scientific community since no optical observations are available during the daytime. So the-early VLF events recorded in sunlit hours can be used to detect red sprites and elves during the day, when optical measurements are not possible.

While we found key insight into the degree of correlation between early VLF events and TLEs and their temporal variations, further data and analysis from a station relatively close to our site is necessary.

Acknowledgement. The authors are thankful to the Ministry of Earth Sciences, Government of India, New Delhi, for financial support in the form of major research project. The authors wish to thank World Wide Lightning Location Network (http://wwlln.net) for providing the lightning location data used in this paper.

\section{References}

Armstrong, W.C. (1983), Recent advances from studies of the Trimpi effect, Antarctic J. US 18, 5, 281-283.

Błęcki, J., M. Parrot, and R. Wronowski (2009), ELF and VLF signatures of sprites registered onboard the low altitude satellite DEMETER, Ann. Geophys. 27, 6, 2599-2605, DOI: 10.5194/angeo-27-2599-2009.

Cummer, S.A., T.F. Bell, U.S. Inan, and D.L. Chenette (1997), VLF remote sensing of high-energy auroral particle precipitation, J. Geophys. Res. 102, A4, 7477-7484, DOI: 10.1029/96JA03721.

Dowden, R.L., C.D.D. Adams, J.B. Brundell, and P.E. Dowden (1994), Rapid onset, rapid decay (RORD), phase and amplitude perturbations of VLF subionospheric transmissions, J. Atmos. Terr. Phys. 56, 11, 1513-1527, DOI: 10.1016/0021-9169(94)90118-X. 
Dowden, R.L., J.B. Brundell, W.A. Lyons, and T.E. Nelson (1996), Detection and location of red sprites by VLF scattering of subionospheric transmissions, Geophys. Res. Lett. 23, 14, 1737-1740, DOI: 10.1029/96GL01697.

Farges, T., E. Blanc, A. Le Pichon, T. Neubert, and T.H. Allin (2005), Identification of infrasound produced by sprites during the Sprite2003 campaign, Geophys. Res. Lett. 32, 1, L01813, DOI: 10.1029/2004GL021212.

Glukhov, V.S., V.P. Pasko, and U.S. Inan (1992), Relaxation of transient lower ionospheric disturbances caused by lightning-whistler-induced electron precipitation bursts, J. Geophys. Res. 97, A11, 16971-16979, DOI: 10.1029/92JA01596.

Haldoupis, C., T. Neubert, U.S. Inan, Á. Mika, T.H. Allin, and R.A. Marshall (2004), Subionospheric early VLF signal perturbations observed in one-toone association with sprites, J. Geophys. Res. 109, A10, A1030, DOI: 10.1029/2004JA010651.

Haldoupis, C., R.J. Steiner., Á. Mika, S. Shalimov, R.A. Marshall, U.S. Inan, T. Bösinger, and T. Neubert (2006), "Early/slow" events: A new category of VLF perturbations observed in relation with sprites, J. Geophys. Res. 111, A11, A11321, DOI: 10.1029/2006JA011960.

Haldoupis, C., M. Cohen, E. Arnone, B. Cotts, and S. Dietrich (2013), The VLF fingerprint of elves: Step-like and long-recovery early VLF perturbations caused by powerful $\pm \mathrm{CG}$ lightning EM pulses, J. Geophys. Res. 118, 8, 5392-5402, DOI: 10.1002/jgra.50489.

Hayakawa, M., O.A. Molchanov, T. Ondoh, and E. Kawai (1996), The precursory signature effect of the Kobe earthquake on VLF subionospheric signals, J. Comm. Res. Lab. 43, 413-418.

Helliwell, R.A., J.P. Katsufrakis, and M.L. Trimpi (1973), Whistler-induced amplitude perturbation in VLF propagation, J. Geophys. Res. 78, 22, 4679-4688, DOI: $10.1029 / J A 078 i 022 p 04679$.

Inan, U.S., D.C. Shafer, W.Y. Yip, and R.E. Orville (1988), Subionospheric VLF signatures of nighttime D region perturbations in the vicinity of lightning discharges, J. Geophys. Res. 93, A10, 11455-11472, DOI: 10.1029/ JA093iA10p11455.

Inan, U.S., T.F. Bell, and J.V. Rodriguez (1991), Heating and ionization of the lower ionosphere by lightning, Geophys. Res. Lett. 18, 4, 705-708, DOI: 10.1029/ 91GL00364.

Inan, U.S., J.V. Rodriguez, and V.P. Idone (1993), VLF signatures of lightninginduced heating and ionisation of the nighttime D-region, Geophys. Res. Lett. 20, 21, 2355-2358, DOI: 10.1029/93GL02620.

Inan, U.S., T.F. Bell, V.P. Pasko, D.D. Sentman, E.M. Wescott, and W.A. Lyons (1995), VLF signatures of ionospheric disturbances associated with sprites, Geophys. Res. Lett. 22, 24, 3461-3464, DOI: 10.1029/95GL03507. 
Inan, U.S., V.P. Pasko, and T.F. Bell (1996a), Sustained heating of the ionosphere above thunderstorms as evidenced in "early/fast" events, Geophys. Res. Lett. 23, 10, 1067-1070, DOI: 10.1029/96GL01360.

Inan, U.S., A. Slingeland, V.P. Pasko, and J.V. Rodriguez (1996b), VLF and LF signatures of mesospheric/lower ionospheric response to lightning discharges, J. Geophys. Res. 101, A3, 5219-5238, DOI: 10.1029/95JA03514.

Inan, U.S., N.G. Lehtinen, S.J. Lev-Tov, M.P. Johnson, T.F. Bell, and K. Hurley (1999), Ionisation of the lower ionosphere by gamma rays from a magnetar: Detection of a low energy (3-10 keV) component, Geophys. Res. Lett. 26, 22, 3357-3360, DOI: 10.1029/1999GL010690.

Inan, U.S., D. Piddyachiy, W.B. Peter, J.A. Sauvaud, and M. Parrot (2007), DEMETER satellite observations of lightning-induced electron precipitation, Geophys. Res. Lett. 34, 7, L07103, DOI: 10.1029/2006GL029238.

Kumar, S., and A. Kumar (2013), Lightning-associated VLF perturbations observed at low latitude: Occurrence and scattering characteristics, Earth Planets Space 65, 1, 25-37, DOI: 10.5047/eps.2012.05.019.

Kumar, S., A. Kumar, and C.J. Rodger (2008), Subionospheric early VLF perturbations observed at Suva: VLF detection of red sprites in the day? J. Geophys. Res. 113, A3, A03311, DOI: 10.1029/2007JA012734.

Lehtinen, N.G., and U.S. Inan (2007), Possible persistent ionization caused by giant blue jets, Geophys. Res. Lett. 34, 8, L08804, DOI: 10.1029/2006GL029051.

Mika, Á. (2007), Very low frequency EM wave studies of Transient Luminous Events in the lower ionosphere, Ph.D. Thesis, Department of Physics, Faculty of Astrophysics and Space Physics, Crete University, Heraklion, Greece, DOI: $10.12681 /$ eadd/16147.

Mika, Á., and C. Haldoupis (2008), VLF studies during TLE occurrences in Europe: A summary of new findings, Space Sci Rev. 137, 1-4, 489-510, DOI: 10.1007/s11214-008-9382-8.

Mika, Á., C. Haldoupis, R.A. Marshall, T. Neubert, and U.S. Inan (2005), Subionospheric VLF signatures and their association with sprites observed during EuroSprite-2003, J. Atmos. Sol.-Terr. Phys. 67, 16, 1580-1597, DOI: 10.1016/j.jastp.2005.08.011.

Mika, Á., C. Haldoupis, T. Neubert, H.T. Su, R.R. Hsu, R.J. Steiner, and R.A. Marshall (2006), Early VLF perturbations observed in association with elves, Ann. Geophys. 24, 8, 2179-2189, DOI: 10.5194/angeo-24-2179-2006.

Mitra, A.P. (1974), Ionospheric Effects of Solar Flares, D. Reidel Publ., Dordrecht.

Moore, R.C., C.P. Barrington-Leigh, U.S. Inan, and T.F. Bell (2003), Early/fast VLF events produced by electron density changes associated with sprite halos, J. Geophys. Res. 108, A10, 1363, DOI: 10.1029/2002JA009816.

NaitAmor, S., M.A. Al-Abdoadaim, M.B. Cohen, B.R.T. Cotts, S. Soula, O. Chanrion, T. Neubert, and T. Abdelatif (2010), VLF observations of ionospheric 
disturbances in association with TLEs from the EuroSprite-2007 campaign, J. Geophys. Res. 115, A7, A00E47, DOI: 10.1029/2009JA015026.

Němec, F., M. Parrot, and O. Santolik (2010), Influence of power line harmonic radiation on the VLF wave activity in the upper ionosphere: Is it capable to trigger new emissions? J. Geophys. Res. 115, A11, A11301, DOI: 10.1029/ 2010JA015718.

Neubert, T., T.H. Allin, E. Blanc, T. Farges, C. Haldoupis, Á. Mika, S. Soula, L. Knutsson, O. van der Velde, R.A. Marshall, U. Inan, G. Sátori, J. Bór, A. Hughes, A. Collier, S. Laursen, and I.L. Rasmussen (2005), Coordinated observations of transient luminous events during the EuroSprite2003 campaign, J. Atmos. Sol.-Terr. Phys. 67, 8-9, 807-820, DOI: 10.1016/ j.jastp.2005.02.004.

Pandey, U., V. Chauhan, and B. Singh (2013), Magnetospherically reflected (MR) whistlers observed in DEMETER satellite and on the ground observation of normal whistlers at low latitudes, Indian J. Radio Space Phys. 42, 2, $97-$ 104.

Parrot, M., J.J. Berthelier, J.P. Lebreton, R. Treumann, and J.L. Rauch (2008), DEMETER observations of EM emissions related to thunderstorms, Space Sci. Rev. 137, 1-4, 511-519, DOI: 10.1007/s11214-008-9347-y.

Parrot, M., J.A. Sauvaud, S. Soula, J.L. Pinçon, and O. van der Velde (2013), Ionospheric density perturbations recorded by DEMETER above intense thunderstorms, J. Geophys. Res. 118, 8, 5169-5176, DOI: 10.1002/jgra. 50460 .

Rodger, C.J. (1999), Red sprites, upward lightning, and VLF perturbations, Rev. Geophys. 37, 3, 317-336, DOI: 10.1029/1999RG900006.

Rodger, C.J. (2003), Subionospheric VLF perturbations associated with lightning discharges, J. Atmos. Sol.-Terr. Phys. 65, 5, 591-606, DOI: 10.1016/S13646826(02)00325-5.

Singh, V., and B. Singh (2010), Scattering of VLF signals from localized perturbations in the lower ionosphere, Indian J. Radio Space Phys. 39, 3, 144-149.

Strangeways, H.J. (1996), Lightning, trimpis and sprites. In: W.R. Stone (ed.), Review of Radio Science 1993-1996, Oxford University Press, Oxford, 740780.

Thomson, N.R. (2010), Daytime tropical D-region parameters from short path VLF phase and amplitude, J. Geophys. Res. 115, A9, A09313, DOI: 10.1029/ 2010JA015355. 